\title{
Chemotherapeutic Management of Hemangiosarcoma in Canines - An Update
}

\author{
Khan Sharun* \\ Division of Surgery, ICAR-Indian Veterinary Research Institute, India
}

Submission: May 02, 2019; Published: May 30, 2019

"Correspondence Author: Khan Sharun, ICAR-Indian Veterinary Research Institute, Izatnagar, Bareilly, Uttar Pradesh, India

\begin{abstract}
Hemangiosarcoma is a malignant vascular endothelial tumor affecting canines. It commonly affects older animals and is also characterized by certain breed predilection. Spleen is the most commonly affected organ in canines but skin associated hemangiosarcomas are less frequent. Management of malignant tumors like hemangiosarcoma should be based on multimodal therapy that combines different techniques like surgical excision, chemotherapy, radiation therapy, and immunotherapy. Even though several chemotherapeutic agents are used alone or as in combinations, it was ineffective in producing a desirable increase in the survival period. Newer agents like Paclitaxel and Resveratrol was found to be effective against hemangiosarcoma cell lines in-vitro. But further studies are required for evaluating the in-vivo effects of such chemotherapeutic agents. Further research should be directed to identify effective chemotherapeutic agents like Paclitaxel and Resveratrol that can be used to manage canine hemangiosarcoma clinically without any side effects.
\end{abstract}

Keywords: Hemangiosarcoma; Canine; Chemotherapy; Doxorubicin

\section{Introduction}

Hemangiosarcoma is a type of malignant tumor that originates from the vascular endothelium. It is mostly seen in canines when compared to other veterinary species. It occurs mainly in older animals and is also found to be related to certain breeds German Shepherd, Golden Retriever, Labrador Retriever, Boxer, Bernese Mountain dog, German Shorthaired Pointer and Flat-Coated Retriever [1]. Sabattini \& Bettini [2], (2009) reported that German shepherd dog breed was the most affected breed in case of hemangioma and hemangiosarcoma. Lamerato-Kozicki [3] evaluated two hypotheses regarding the origin of hemangiosarcoma in canine and concluded that they are arising from the transformed hemangioblastic stem cells. This ruled out the hypothesis that hemangiosarcoma are originating from the differentiated vascular endothelial cells due to mutation. A similar study reported that hemangiosarcoma arises from multipotent progenitors that has the ability to differentiate into multiple lineages as a part of adaptive process [4]. Benjamin et al. [5] reported that hemangiosarcoma can be developed experimentally in dogs by exposing them to high levels of ionizing radiations. Hemangiosarcoma in canines commonly affects the spleen. Skin associated hemangiosarcomas are less frequently seen in canines [6]. Cutaneous hemangiosarcomas are classified into three stages depending on their histological location as dermal, hypodermal, and deep. Among them dermal (Stage I) cutaneous hemangiosarcoma was found to be less severe and had higher survival times when compared to other stages. Hypodermal (Stage II) and Deep (Stage III) were having only shorter survival periods. In deep (Stage III) cutaneous hemangiosarcoma, the muscle layer below the skin are also involved [7].

Post-mortem examination of dogs died due to hemangiosarcoma revealed presence of multi-organ metastasis [8]. Waters et al. [9] reported that the dogs having pulmonary metastasis will have eight times greater risk of having brain metastasis when compared with the dogs without pulmonary metastasis. Hence screening for lung metastasis in hemangiosarcoma can be also used as an indication of intracranial lesion and associated symptoms. Complete excision is the choice of treatment in case of non-visceral hemangiosarcoma. Surgical removal of non-visceral hemangiosarcoma can make the patient clinically normal for at least a period of one year. Incomplete removal of tumor in such cases will result in recurrence [10]. Tsuji et al. [11] reported a case of canine cutaneous hemangiosarcoma characterized by multiple cutaneous and subcutaneous masses in the left forelimb from elbow to digits. The tumor showed poor demarcation and the overlying skin was ulcerated. Amputation of the limb can 


\section{Cancer Therapy \& Oncology International Journal}

be attempted in cases of hemangiosarcomas of bones and muscles if they are localized to a single limb. Radiation therapy can be used for palliative treatment in managing hemangiosarcoma in dogs. Reduction in tumor size was observed in non-splenic hemangiosarcoma affected canine patients when treated with radiation therapy [12].

\section{Chemotherapy}

Doxorubicin is the chemotherapeutic agent used commonly in case of hemangiosarcoma both as a single agent $[13,14]$ and as a combination therapy with other agents like cyclophosphamide [15] dacarbazine [16]. Doxorubicin is also used as a threedrug combination chemotherapy with cyclophosphamide and vincristine in managing hemangiosarcoma in dogs [17]. U'ren et al. [18] evaluated the safety and efficacy of allogeneic tumor lysate vaccine directed against hemangiosarcomas in canines. It was found that vaccinating the dogs undergoing chemotherapy using doxorubicin produced strong humoral immune response and had mean survival period of 182 days. Combining Immunotherapy with chemotherapy can improves the mean survival period of canine patients affected with hemangiosarcoma.

The drug paclitaxel used as water-soluble nanoparticle micellar formulation was found to be effective against canine hemangiosarcoma cell lines when evaluated in-vitro. The action against hemangiosarcoma was due to the apoptosis initiating activity of the drug [19]. The 50\% inhibitory concentration recommended by the study was found to be clinically achievable. Further in-vivo studies are required to evaluate the efficacy of paclitaxel against hemangiosarcoma.

Resveratrol, a naturally found non-flavonoid polyphenolic compound was found to be having growth-inhibitory effect on two hemangiosarcoma cell lines thus making it a suitable candidate for incorporating into doxorubicin based chemotherapeutic regimens used to manage hemangiosarcoma in canines. The combination of resveratrol with doxorubicin increased the cytotoxic effect of doxorubicin without increasing its cardio toxic effects [20].

\section{Conclusion}

During the past few years several anti-cancer agents are been evaluated for its efficacy against many malignant tumors. The main reason for such a trend is mostly due to the inability of anthracycline-based chemotherapeutic regimens against malignant tumors like hemangiosarcoma. Management of malignant tumors should be based on multimodal therapy that combines different techniques like surgical excision, chemotherapy, radiation therapy, and immunotherapy. Rather than going for chemotherapy alone combination therapy can be a better option in managing canine hemangiosarcoma. Further in-vivo studies are necessary for identifying newer agents that can effectively manage canine hemangiosarcoma. Recent studies give a hope for the development of effective chemotherapeutic agent since several new chemotherapeutic agents were found to be effective against several hemangiosarcoma cell line

\section{References}

1. Göritz M, Müller K, Krastel D, Staudacher G, Schmidt P, et al. (2013) Canine splenic haemangiosarcoma: influence of metastases, chemotherapy and growth pattern on post-splenectomy survival and expression of angiogenic factors. J Comp Pathol 149(1): 30-39.

2. Sabattini S, Bettini G, (2009) An immunohistochemical analysis of canine haemangioma and haemangiosarcoma. J Comp Pathol 140(23): $158-168$.

3. Lamerato KAR, Helm KM, Jubala CM, Cutter GC, Modiano JF (2006) Canine hemangiosarcoma originates from hematopoietic precursors with potential for endothelial differentiation. Exp Hematol 34(7): 870878.

4. Gorden BH, Kim JH, Sarver AL, Frantz AM, Breen M, et. al (2014) Identification of three molecular and functional subtypes in canine hemangiosarcoma through gene expression profiling and progenitor cell characterization. Am J Pathol 184(4): 985-995.

5. Benjamin SA, Hahn FF, Chiffelle TL, Boecker BB, Hobbs CH, et al. (1975) Occurrence of hemangiosarcoma's in beagles with internally deposited radionuclides. Cancer research 35(7): 1745-1755.

6. Gross TL, Ihrke PJ, Walder EJ, Affolter VK, (2005) Vascular tumors. Skin Diseases of the Dog and Cat: Clinical and Histopathologic Diagnosis, ( $2^{\text {nd }}$ edn). TL Gross, PJ Ihrke, EJ Walder, and VK Affolter (Eds.) Blackwell Publishing, Iowa pp: 944.

7. Ward H, Fox LE, Calderwood-Mays MB, Hammer AS, Couto CG (1994) Cutaneous hemangiosarcoma in 25 dogs: a retrospective study J Vet Intern Med 8(5): 345-348.

8. Sorenmo K, Duda L, Barber L, Cronin K, Sammarco C, et al. (2000) Canine hemangiosarcoma treated with standard chemotherapy and minocycline. J Vet Intern Med 14(4): 395-398.

9. Waters DJ, Hayden DW, Walter PA, (1989) Intracranial lesions in dogs with hemangiosarcoma. Journal of veterinary internal medicine $3(4)$ : 222-230.

10. Schultheiss PC (2004) A retrospective study of visceral and nonvisceral hemangiosarcoma and hemangiomas in domestic animals. J Vet Diagn Invest 16(6): 522-526.

11. Tsuji N, Furukawa S, Ozaki K (2013) Cutaneous hemangiosarcoma in a dog. J Toxicol Pathol 26(2):193-195.

12. U'ren Hillers KR, Lana SE, Fuller CR LaRue SM (2007) Effects of palliative radiation therapy on nonsplenic hemangiosarcoma in dogs. J Am Anim Hosp Assoc 43(4): 187-192.

13. Ogilvie GK, Powers BE, Mallinckrodt C H, Withrow SJ, (1996) Surgery and doxorubicin in dogs with hemangiosarcoma. J Vet Intern Med 10(6): 379-384.

14. Wiley JL, Rook KA, Clifford CA, Gregor TP, Sorenmo KU (2010) Efficacy of doxorubicin-based chemotherapy for non-resectable canine subcutaneous haemangiosarcoma. Vet Comp Oncol 8(3): 221-233.

15. Bulakowski EJ, Philibert JC, Siegel S, Clifford CA, Risbon R, et al (2008) Evaluation of outcome associated with subcutaneous and intramuscular hemangiosarcoma treated with adjuvant doxorubicin in dogs: 21 cases (2001-2006) J Am Vet Med Assoc 233(1): 122-128.

16. Finotello R, Stefanello D, Zini E, Marconato L, (2017) Comparison of doxorubicin-cyclophosphamide with doxorubicin-dacarbazine for the adjuvant treatment of canine hemangiosarcoma. Vet Comp Oncology 15(1): 25-35. 
17. Hammer AS, Couto CG, Filppi J, Getzy D, Shank K, (1991) Efficacy and toxicity of VAC chemotherapy (vincristine, doxorubicin, and cyclophosphamide) in dogs with hemangiosarcoma. J Vet Intern Med 5(3): 160-166.

18. U'ren LW, Biller BJ, Elmslie RE, Thamm DH, Dow SW (2007) Evaluation of a novel tumor vaccine in dogs with hemangiosarcoma. J Vet Intern Med 21(1): 113-120.
19. Reckelhoff CR, Lejeune A, Thompson PM, Shiomitsu K (2019) In vitro effects of the chemotherapy agent water-soluble micellar paclitaxel (Paccal Vet) on canine hemangiosarcoma cell lines. Veterinary and comparative oncology 17(1): 32-41.

20. Carlson A, Alderete KS, Grant MKO, Seelig DM, Sharkey LC, et al. (2018) Anticancer effects of resveratrol in canine hemangiosarcoma cell lines. Veterinary and comparative oncology 16(2): 253-261.

\section{Your next submission with Juniper Publishers will reach you the below assets}

- Quality Editorial service

- Swift Peer Review

- Reprints availability

- E-prints Service

- Manuscript Podcast for convenient understanding

- Global attainment for your research

- Manuscript accessibility in different formats

( Pdf, E-pub, Full Text, Audio)

- Unceasing customer service

Track the below URL for one-step submission https://juniperpublishers.com/online-submission.php 